\title{
Amelioration of Cognitive Deficits, Oxidative Damage, Neurochemical Alteration by Bauhinia purpurea (stem bark) on Scopolamine Induced Amnesia
}

\author{
Prakash Ramakrishnan ${ }^{1, *}$, Panneerselvam Perumal ${ }^{2}$, Dhivya Ramadoss ${ }^{3}$, Parthiban Ramalingam ${ }^{4}$, Subash Chandra Boss Vijayarangan ${ }^{5}$ \\ 'Department of Pharmacology, Crescent School of Pharmacy, BS Abdur Rahman Crescent Institute of Science and Technology, Chennai, Tamil Nadu, INDIA. \\ 2Department of Pharmaceutical Chemistry, Faculty of Pharmacy, Bharath Institute of Higher Education and research, Chennai, Tamil Nadu, INDIA. \\ 3Department of Pharmacology, Faculty of Pharmacy, Dr MGR Educational and Research Institute, Chennai, Tamil Nadu, INDIA. \\ ${ }^{4}$ Department of Pharmaceutics, Surya School of Pharmacy, Villupuram, Tamil Nadu, INDIA \\ ${ }^{5}$ Department of Pharmaceutical Analysis, Surya School of Pharmacy, Villupuram, Tamil Nadu, INDIA.
}

\begin{abstract}
Aim: To evaluate the anti-amnesia effect of Bauhinia purpurea in Scopolamine induced amnesia in rats. Materials and Methods: A total of 30 rats were divided into 5 groups 6 rats in each. Group I considered as normal control. Group II served as negative control. Group III, IV and V were treated with Donepezil (3 $\mathrm{mg} / \mathrm{kg}$ ), ethanolic extract of Bauhinia purpurea $200 \mathrm{mg} / \mathrm{kg}$ and $400 \mathrm{mg} / \mathrm{kg}$ respectively for 14 consecutive days followed by single administration of Scopolamine (3 $\mathrm{mg} / \mathrm{kg})$ to all the groups except group I. Cognitive performance was assessed by the Morris water maze, elevated plus maze and passive avoidance paradigm. Acetyl cholinesterase enzyme level, biochemical markers such as lipid peroxidation, reduced glutathione and $\beta$ amyloid 142 level, Neurotransmitters including dopamine and serotonin and histopathological study of rat brain were estimated. Results: Bauhinia purpurea and Donepezil rats showed significant increase in escape latency, step-through latency and decreased transfer latency in respective cognitive models of the Morris water maze, passive avoidance test and elevated plus maze. Additionally, Bauhinia purpurea extract remarkably promoted the cholinergic neurotransmission, decreasing $\beta$ amyloid protein and protected against the oxidative stress damage as indicated by, increasing reduced glutathione level, lowering the level of
\end{abstract}

lipid peroxidation, restored dopamine and serotonin level in the brain Furthermore, histopathological studies revealed the reversal of neuronal damage in the treatment group compared to Scopolamine treated rats. Conclusion: Bauhinia purpurea extract showed promising antiamnesia activity against scopolamine induced amnesia in rats. This could be attributed to its brain acetyl cholinesterase level, $\beta$ amyloid level inhibition, antioxidant activity and alteration in neurotransmitters level.

Key words: Bauhinia purpurea, Neuroprotective, Acetylcholinesterase, $\beta$ amyloid protein, Scopolamine.

Correspondence

Dr. R.Prakash., M.Pharm., Ph.D.,

Associate Professor, Department of Pharmacology, Crescent School of Pharmacy, BS Abdur Rahman Crescent Institute of Science and Technology, Chennai, Tamil Nadu, INDIA.

Phone: +91-9940634459

Email: prakasheeba@rediffmail.com

DOI: 10.5530/jyp.2020.12.66

\section{INTRODUCTION}

Alzheimer's disease (AD) is a widespread neurodegenerative condition that causes memory loss and dementia and the aging population is a major health concern. This is characterized by the development of senile plaques which are rich in insoluble aggregates of $\beta$ amyloid and neurofibrillary tangles in the brain, neurotransmission deficiency, neuroinflammation, neuronal death and free radical formation. ${ }^{1}$ Thirty million people worldwide are affected by dementia and 4.6 million cases annually are well documented according to $\mathrm{AD}$ society analysis. ${ }^{2}$ The primary cause of $\mathrm{AD}$ such as decrease in the level of acetyl choline, oxidative stress followed by impaired memory. Memory is one of an individual's important roles in remembering events, storing and maintaining information over short and long periods. ${ }^{3}$ Induction of cognitive deficiencies by cholinergic antagonism that is similar to Alzheimer's cognitive symptomology. ${ }^{4}$

Scopolamine (Scop) is cholinergic antagonist and can induce cognitive dysfunction in rodents as well as to humans by decreasing the CNS efficacy of ACh in animals and humans cause impairment in learning and memory. ${ }^{5}$ Currently, AD can be treating with acetyl cholinesterase inhibitors with fewer benefits and also accompanied by adverse effects including hepatotoxicity and nausea with short half-lives. ${ }^{6}$ According to the estimation World Health Organization (WHO) that majority of the population presently uses herbal drugs for many health issues such as neurodegenerative disease, diabetes and cancer etc., Herbal drugs may provide a new source of beneficial neuropsychotropic drugs. ${ }^{7,8}$

Bauhinia purpurea L. belonging to the family Leguminosae, grows small to medium sized deciduous tree upto $17 \mathrm{~m}$ tall. Parts of this plant have been used in the field of medicines traditionally to treat various kinds of disease including body pain, rheumatism, fever, dropsy, stomach tumour, skin diseases, septicemia and diarrhea., ${ }^{910}$ Analgesic, anti-inflammatory, antipyretic, antidiabetic, free radical scavenging and thyroid hormonestimulating activities were scientifically documented. ${ }^{11-13}$ Several plant constituents including foliar flavonoids, flavones, flavonone glycosides were reported. ${ }^{14,15}$ However, its antiamnesic activity has yet to be investigated. Hence, the present study was conducted to evaluate the antiamnesic effect of Bauhinia purpurea (stem bark) in scopolamine induced amnesia in rats.

\section{MATERIALS AND METHODS}

\section{Plant Material and Extraction}

Bauhinia purpurea is an accepted plant name and in the listed of plants (www. the plant list.org). The plant material was obtained from Tirunelveli

This is an open access article distributed under the terms of the Creative Commons Attribution-NonCommercial-ShareAlike 4.0 License, which allows others to remix, tweak, and build upon the work non-commercially, as long as the author is credited and the new creations are licensed under the identical terms. 
dist, Tamil Nadu, India. It was authenticated by Dr. Pandikumar, Scientist, Department of Ethanopharmacology, Loyola Institute of Entomology and Chennai. The stem bark was cleaned, dried and coarsely powdered. The coarse powder was weighed and extracted with 70\% ethanol (68$78^{\circ} \mathrm{C}$ ) in Soxhlet apparatus. Using a rotary evaporator, the extract was concentrated to dryness and eventually air-dried thoroughly to clear all traces of the solvent. The yields of the ethanol extract were found to be $1.0 \%(\mathrm{w} / \mathrm{w})$, respectively

\section{Animals}

Adult male wistar rats (weighing 180- 200g: 30 rats) were procured from CL Baid Metha College of Pharmacy, Chennai and divided into five groups of six in each. Rats were housed in cages in groups of six per cage and maintained under natural light and dark cycle and standard laboratory conditions. Before going to conduct the experiment rats should be acclimatized for a week with ad libitum free access to food and water. Behavioral tests were performed in a quiet environment from 9.00 am to 11.00 am to prevent circadian variability. All the experimental procedures were carried out in accordance with the CPCSEA guidelines. IAEC approval No. IAEC/LX/05/CLBMCP/2018.

\section{Drugs and Chemicals}

Scopolamine (Sigma Aldrich, New Delhi), Donepezil (Eisai Pharmaceuticals Ltd., Mumbai). ELISA kit for rat $\mathrm{A} \beta^{1-42}$ (YH Bioresearch Laboratory, Shanghai, China). All other chemicals and reagents unless specified were of analytical grade. All the drug solutions were freshly prepared and use.

\section{Experimental design}

Three behavioral models were used to assess learning and memory, namely Morris water maze (MWM), elevated plus maze (EPM) and modified passive avoidance study. Rats were randomly divided into five groups ( $n=6 /$ group); Group I- Normal control (Vehicle $0.9 \% \mathrm{Nacl}$ i.p.), Group II - Negative control (Vehicle + scop $3 \mathrm{mg} / \mathrm{kg} .$, i.p.,) Group III - Standard drug (Donepezil $3 \mathrm{mg} / \mathrm{kg}$., i. p.+ scopolamine $3 \mathrm{mg} / \mathrm{kg}$, i.p.), Group IV- Low dose ethanolic extract of Bauhinia purpurea (EEBP $200 \mathrm{mg} / \mathrm{kg}$., p.o.+ Scopolamine $3 \mathrm{mg} / \mathrm{kg}$, i.p ) and Group V- High dose of ethanolic extract of Bauhinia purpurea (EEBP $400 \mathrm{mg} / \mathrm{kg}$., p.o.+ Scopolamine $3 \mathrm{mg} / \mathrm{kg}$, i.p). The rats were administered every $24 \mathrm{~h}$ interval with respective drugs for 14 consecutive days. Memory evaluation parameter such as MWM, EPM and passive avoidance acquisition trail was carried out on the 14th day, intraperitoneal administration of Scopolamine $3 \mathrm{mg} / \mathrm{kg}$ was administered to all the groups except normal control group after completion of acquisition trail. The timeline scheme of the experiment is shown in Figure 1.

\section{Screening Methods for Amnesia}

\section{Elevated plus-maze test}

Memory enhancement index screening was conducted in rats using elevated plus maze. Every rat was placed in the elevated plus maze apparatus at the end of an open arm. The time required for each rat to enter to the closed arm was deemed to be transfer latency (TL). Each rat allotted cutoff time is $180 \mathrm{~s}$ and the retention trial was performed 24 $\mathrm{hr}$ after the first trial, transfer latency was reported in a manner similar to that previously described. Shortened transfer latency was used as an indicator of memory improvement. ${ }^{16}$

\section{Morris water maze}

Spatial learning and memory were evaluated by the Morris water maze. The procedure included two steps. The first step was the place navigation test from day 1 to 4 , in which the escape latency (EL) (the time required to escape onto the hidden platform) was used to evaluate learning and memory function. Mice that found the platform were allowed to remain on the platform for $20 \mathrm{~s}$ and were then returned to the home cage. If mice did not reach the platform within $120 \mathrm{~s}$, it was gently guided to the platform by the experimenter, where it remained for $20 \mathrm{~s}$. The last trial was regarded as the probe test. The second step was the spatial probe test on day 5 after removal of the platform and after the space navigation test, which was performed to test the ability of mice to find the removed platform by memory. ${ }^{17}$

\section{Passive shock avoidance test}

The step-through passive avoidance apparatus consisted of an illuminated chamber $(11.5 \mathrm{~cm} \hat{A} 9.5 \mathrm{~cm} \hat{A} 11 \mathrm{~cm})$ attached to a darkened chamber $(23.5 \mathrm{~cm}$ A $9.5 \mathrm{~cm} \mathrm{Â} 11 \mathrm{~cm})$ containing a metal floor that could deliver foot shocks. The two compartments were separated by a guillotine door. The illuminated chamber was lit with a $25 \mathrm{~W}$ lamp. Briefly, mice were placed in the dimly lit room containing the apparatus $0.5 \mathrm{~h}$ before training to acclimatize to the new environment. Each mouse was then placed individually into the illuminated chamber, facing away from the door to the dark chamber and allowed to acclimatize for $1 \mathrm{~min}$. As soon as the mouse entered the dark chamber, the door was slid back into place, triggering a mild foot shock $(0.3 \mathrm{~mA}, 50 \mathrm{~Hz}, 5 \mathrm{~s})$. The mouse was then immediately removed from the chamber and returned to its home cage. The latency (time used to change compartment) was recorded. The retention test was conducted $24 \mathrm{~h}$ later with the mouse again being placed in the illuminated chamber and subjected to the same protocol in the absence of foot shock. The upper time limit was set at 300s. ${ }^{18}$

\section{Collection of Brain Sample}

The brain were removed carefully from the skull by cervical dislocation and weighed. Ten percent $\mathrm{w} / \mathrm{v}$ brain homogenate was then prepared by homogenizing it in ice chilled phosphate buffer $(\mathrm{pH} 8,0.1 \mathrm{M})$. The homogenate was subsequently centrifuged using a refrigerated centrifuge at $3000 \mathrm{rpm}$ for $10 \mathrm{~min}$ and the supernatant was separated and used for the biochemical estimations.

\section{Antioxidant Estimation}

\section{Estimation of Lipid Peroxidation}

About $0.2 \mathrm{~mL}$ of brain homogenate, $0.2 \mathrm{~mL}$ of sodium dodecyl sulfate, $1.5 \mathrm{~mL}$ of acetic acid, and $1.5 \mathrm{~mL}$ of thiobarbituric acid were added. The mixture was made up to $4 \mathrm{~mL}$ with water and then heated in a water bath

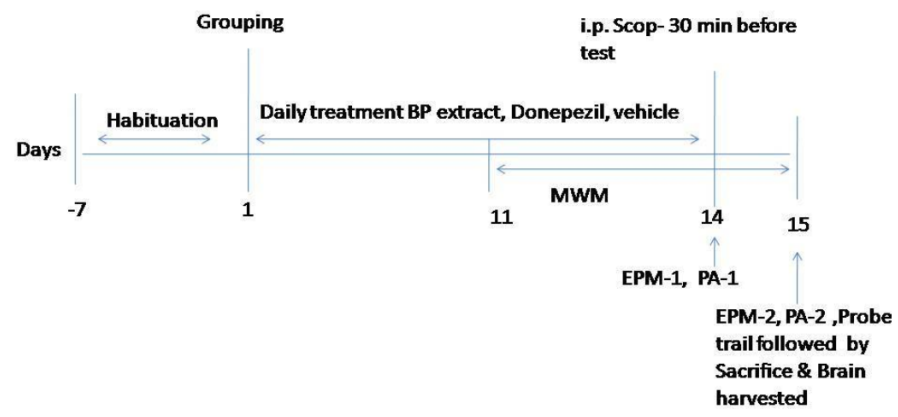

Figure 1: Schematic description of experimental design: After 7 days acclimatization period, animals were divided into 5 Groups: Control group; Scop group (3mg/kg,i.p); Scop+ Donepezil group ( $3 \mathrm{mg} / \mathrm{kg}$ ) and Scop + EEBP (200 and $400 \mathrm{mg} / \mathrm{kg} .$, p.o.). Rats were pretreated with EEBP and DNP for 14 days followed by single challenge of Scop. Memory evaluation parameter such as Morris water maze, elevated plus maze and passive avoidance were assessed. Following the behavioral tests all rats were sacrificed and brain were harvested for further biochemical studies. 
at $95^{\circ} \mathrm{C}$ for $60 \mathrm{~min}$. After cooling, $1 \mathrm{~mL}$ of water and $5 \mathrm{~mL}$ of nbutanol/ pyridine mixture were added and shaken vigorously. After centrifugation at $4000 \mathrm{rpm}$ for $10 \mathrm{~min}$, the organic layer was taken and its absorbance was read at $532 \mathrm{~nm}$. The levels were expressed as nmoles of MDA/min/ mg protein in brain homogenate. ${ }^{19}$

\section{Estimation of Reduced Glutathione}

The reaction mixture containing $1 \mathrm{~mL}$ of phosphate buffer, $0.5 \mathrm{~mL}$ of ethylenediamine tetra acetic acid (EDTA), $0.5 \mathrm{~mL}$ of oxidized glutathione and $0.2 \mathrm{~mL}$ of NADPH was made up to $3 \mathrm{~mL}$ with distilled water. After the addition of $0.1 \mathrm{~mL}$ of tissue homogenate, the change in optical density at $340 \mathrm{~nm}$ was monitored for $2 \mathrm{~min}$ at $30 \mathrm{~s}$ intervals. One unit of the enzyme activity was expressed as moles of NADPH oxidized/ $\mathrm{min} / \mathrm{mg}$ protein. ${ }^{20}$

\section{Neurotransmitters Estimation}

\section{Estimation of Acetyl cholinesterase Enzyme in Brain}

Twenty milligram of brain tissue/mL of phosphate buffer was homogenized in a PotterElvehjem homogenizer. About $0.4 \mathrm{~mL}$ of brain tissue was added containing $206 \mathrm{~mL}$ of $0.1 \mathrm{M}$ phosphate buffer. One hundred microliter of the DTNB reagent was added to the photocell. The absorbance was measured at $412 \mathrm{~nm}$ then acetylthiocholine iodide was added. The enzyme activity is expressed as $\mu \mathrm{mol} / \mathrm{min} / \mathrm{mg}$ tissue. ${ }^{21}$

\section{Estimation of $\beta$ - Amyloid ( $A \beta^{1-42}$ )}

Homogenized brain in phosphate buffer and centrifuged at $5000 \mathrm{rpm}$ and the supernatant was used for the detection of $A \beta 142$. The absorbance was measured in the multiscan spectrum spectrophotometer at optical density $450 \mathrm{~nm}$.

\section{Estimation of Dopamine}

About $0.2 \mathrm{~mL}$ of aqueous phase, $0.4 \mathrm{M} \mathrm{HCl}$ and $0.1 \mathrm{~mL}$ of EDTA/ sodium acetate buffer were added, followed by $0.1 \mathrm{~mL}$ of iodine solution for oxidation. The reaction was stopped after $2 \mathrm{~min}$ by addition of 0.1 $\mathrm{mL} \mathrm{Na} \mathrm{SO}_{3}$ solution. The solution was then heated to $100^{\circ} \mathrm{C}$ for $6 \mathrm{~min}$ when the tissue homogenate reaches room temperature were read using spectrofluorimeter. The readings were taken at $330-375 \mathrm{~nm}$ for DA. ${ }^{22}$

\section{Estimation of Serotonin}

Three milliliter of brain homogenate in $0.1 \mathrm{~mL}$ of hydrochloric acidnbutanol for one minute in glass homogenizer. The sample was centrifuged for $10 \mathrm{~min}$ at $2000 \mathrm{rpm}$. Supernatant phase with $0.2 \mathrm{~mL}$ of heptane and $0.025 \mathrm{~mL}$ of $\mathrm{HCl} 0.1 \mathrm{~mL}$ was removed and added to the Eppendorf tubes. After $10 \mathrm{~min}$ of vigorous shaking, the tubes were centrifuged under the same condition as above to separate the two phases. The aqueous phase was taken and phthaldialdehyde was added. The fluorophore was developed by heating to $100^{\circ} \mathrm{C}$ for $10 \mathrm{~min}$; after the sample reached the equilibrium, the intensity was measured at 360-470 $\mathrm{nm}$ in the spectrofluorimeter. ${ }^{23}$

\section{Histopathological Studies}

The rat brain was collected and isolated with formalin solution $10 \%$. Then, the brains were routinely embedded in paraffin and stained with hematoxylineosin. The hippocampal lesions were assessed microscopically at $\times 40$ magnification

\section{Statistical Analysis}

The results are reported as the mean \pm SEM of the mean analysis of variance followed by the Tukey's multiple comparison tests were used for comparison. Differences were considered significantly at $P<0.05$.

\section{RESULTS}

\section{Effect of Bauhinia purpurea extract on transfer latency in elevated plus maze}

The memory function was tested on long-term spatial memory using the EPM test. Time required for each rat to enter from the open arm into the closed arm was known as the transfer latency period. Scopolamine treated rats produced significantly increased $(P<0.001)$ in transfer latency on retention trail compared to control rats which indicates learning and memory impairment. Pretreated with BP extract in both doses $(P<0.01, P<0.001)$ and Donepezil rats were produced significantly decreased $(P<0.001)$ the transfer latency when compared to scopolamine treated rats. (Table 1$)$

\section{Effect of Bauhinia purpurea extract on escape latency in morris water maze}

The escape latency time (ELT) is the time taken by the rats to locate the secret platform in the labyrinth of water that was used as a measure to determine the performance of the treated rats. The scopolamine-treated rats showed significantly prolonged the ELT compared to normal rats on fourth day of the acquisition period. On $5^{\text {th }}$ day, time spent in the particular quadrant was significantly reduced compared to control rats $(P<0.001)$. In acquisition trail, pretreatment with BP extract was found significantly decrease the ELT when compared to Scopolamine treated rats. On day five, $\mathrm{BP}$ extracts $(P<0.01, P<0.001)$ and Donepezil $(P<0.001)$ pretreatment groups exhibited significantly increased time spent in the target quadrant compared with scopolamine rats (Table 1).

\section{Effect of Bauhinia purpurea extract on latency time in passive avoidance test}

On Day 1, Scopolamine treated rats resulted in a significantly $(P<0.001)$ shorter latency time compared with the control group. The shorter retention latency suggests impairment in learning and memory. Pretreated with BP extracts $(P<0.01, P<0.001)$ and Donepezil rats significantly $(P<0.001)$ increased the latency time compared with the scopolamine rats. (Table 1).

\section{Effect of Bauhinia purpurea extract on scopolamine induced oxidative stress}

Scopolamine treated rats induced oxidative damage indicated by the significant decreased $(P<0.001)$ GSH content and increased $(P<0.001)$ the level of MDA in the brain compared to control rats. Pretreated with BP extract and Donepezil treated rats produced significantly decreased the MDA level $(P<0.01, P<0.001$ and $P<0.001)$ and increased the GSH level $(P<0.001)$ compared to Scopalamine treated rats (Figure 2a, b).

\section{Effect of Bauhinia purpurea extract on scopolamine induced Acetylcholinestrease level}

Rats were treated with single administration of Scopolamine rats significantly increased $(P<0.001)$ the AChE activity compared to normal control rats. Treatment with Bauhinia purpurea extracts and Donepezil rats significantly $(P<0.01, P<0.001$ and $P<0.001)$ reverse the Scopolamine induced increase the $\mathrm{AChE}$ activity (Figure $3 \mathrm{a}$ ).

\section{Effect of Bauhinia purpurea extract on scopolamine induced $\beta$ amyloid ${ }^{1-42}$ level in brain homogenate}

The concentration of $\beta$ amyloid $^{1-42}$ level increased significantly in the treatment of scopolamine treated compared to control rats $(P<0.001)$. Pretreatment with Bauhinia purpurea extract and Donepezil rats 
significantly decreased the concentration of $A \beta^{1-42}$ as compared to scopolamine treated group (Figure $3 b$ ).

\section{Effect of Bauhinia purpurea extract on scopolamine induced dopamine and serotonin level in brain homogenate}

Scopolamine treated rats significantly altered the levels of neurochemicals such as DA and 5-HT in the rat's brain hippocampus region. Specifically, the level of DA and 5-HT increased significantly $(P<0.001)$ compared to control rats. Nevertheless, high dose of Bauhinia purpurea $(P<0.05$ and $P<0.01)$ and Donepezil rats $(P<0.01)$ significantly reversed the both the neurochemicals level such as DA and 5-HT produced by scopolamine treated rats (Table 2).

\section{Effect of Bauhinia purpurea extract on scopolamine induced neuronal damage in hippocampal region}

Scopolamine treated rats showed degeneration and decrease in number of neuronal cells along with edema and psychotic nuclei. Pretreated with Bauhinia purpurea extract significantly recovered the neurodegeneration, edematous nuclei and congestion of neurons by dose dependently and Donepezil treated rats significantly ameliorate the neurodegeneration and decrease in neuronal cells compared to Scopolamine treated rats (Figure 4).

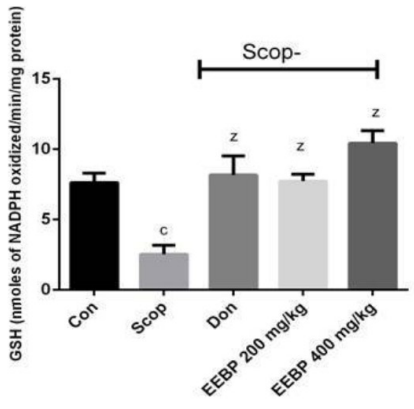

Figure 2a

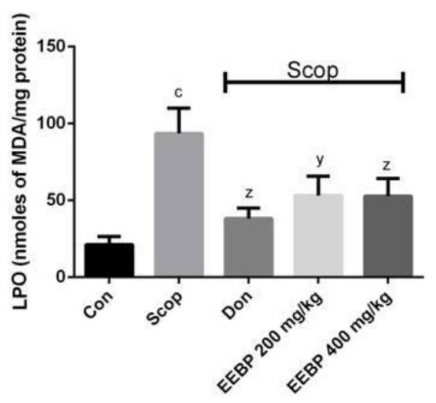

Figure 2b

Figure 2: Effect of Bauhinia purpurea extract on scopolamine induced oxidative stress a. Reduced Glutathione b. Lipid Peroxidation levels in the rat brain homogenates. Values represent in mean \pm SEM $(n=3): c P<0.001$ compared to control rats. $y P<0.01$ and $z P<0.001$ compared to Scopolamine rats, one way ANOVA followed by Tukey's post hoc test.

Figure. 3 (a)
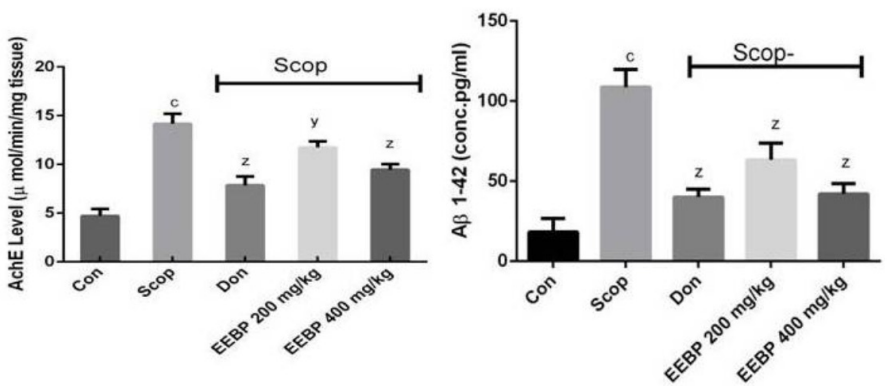

Figure 3: Effect of Bauhinia purpurea extract on scopolamine induced (a). AChE level (b). $\beta$ amyloid1 42 level in brain homogenate. Values represent in mean \pm SEM $(n=3): c P<0.001$ compared to control rats. $y P<0.01$ and $z P<0.001$ compared to Scopolamine rats using one way ANOVA followed by Tukey's post hoc test.

\section{DISCUSSION}

In the Indian medical system, bauhinia purpurea was prescribed for various nervous-related disorders, including convulsions, delirium, asthma and anti-inflammatory agents, ${ }^{24,25}$ but no neuroprotective research has been investigated till date. Our current study reveals the first evidence that Bauhinia purpurea (stem bark) has antiamnesic effect on scopolamine induced amnesia in rats. The effect BP extract was assessed by screening methods including Morris water maze, elevated plus maze, passive avoidance were performed. Additionally, using the homogenates of brain tissues levels of neurochemicals, oxidative markers, histopathological studies were also performed.

In the present study, to evaluate the effect of BP extract on Scop-induced amnesia in rats, three types of cognitive memory tasks such as EPM, ${ }^{26,27}$ $\mathrm{MWM}^{28}$ and Passive Avoidance Task ${ }^{29}$ were used. For the time, BP extract treatment was found to strongly improve the impaired memory in the Scop-treated rats in the EPM task which indicates the long-term animal spatial memory enhancing effects. Scopolamine-treated rats increased the latency duration of escape during the acquisition process and decreased in the time spent in the probe trail in the target quadrant. Treatment with BP extract reverse the Scop- induced memory deficits in acquisition trail as well as on probe trail. The rat goes into the dark chamber, gets a painful electric shock in the first trial. Indeed, the animal's ability to learn and memorize was demonstrated by avoiding entry into the dark chamber. ${ }^{30}$ The results of the current study reveal that Scop- treated rats significantly reduced the latency time in the passive avoidance test and learning and memory function deficits. It is consistent with previous results that systemic administration of Scopproduced impaired in cognitive function in rodents and humans. ${ }^{31}$ Scopinduced memory deficits were reversed by pretreatment with Bauhinia purpurea extract proven the antiamnesic effect based on the behavioural study. In our in vivo study as mentioned earlier studies could reverse scopolamine-induced memory impairment. ${ }^{32}$

Scop-induced amnesia has also been linked with enhanced oxidative stress damage in the brain particularly in the region of hippocampus it is

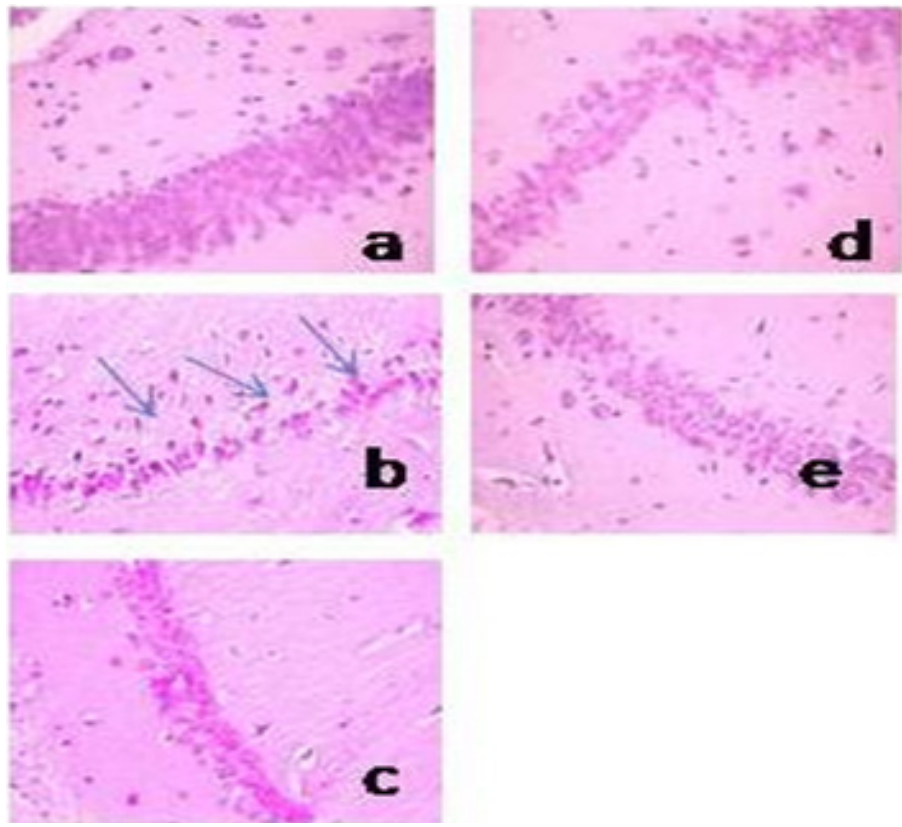

Figure 4: Histopathological photographs of hippocampal region a. Normal control b. Scopalamine c. Donepezil d. EEBP low dose e. EEBP high dose. Degeneration and decrease in number of neuronal cells along with edema and pyknotic nuclei in Scop-treated group (Blue arrow) 


Table 1: Effect of Bauhinia purpurea and Donepezil on Elevated Plus maze, Morris water maze and Passive
avoidance test in Scop-induced amnesia in rats.
\begin{tabular}{cccc}
\hline Groups & Transfer Latency (s) & Time spent in target quadrant (s) & Escape Latency (s) \\
\hline Normal control & $10.28 \pm 4.23$ & $5.28 \pm 2.24$ & $15.16 \pm 4.56$ \\
Scopalamine control & $28.15 \pm 6.27^{\mathrm{c}}$ & $1.26 \pm 0.98^{\mathrm{c}}$ & $4.67 \pm 1.78^{\mathrm{c}}$ \\
Donepezil (3mg/kg) + Scop (3 & $13.27 \pm 2.18^{\mathrm{z}}$ & $4.98 \pm 1.90^{\mathrm{z}}$ & $11.05 \pm 3.68^{\mathrm{z}}$ \\
$\mathrm{mg} / \mathrm{kg})$ & & & \\
EEBP (200mg/kg)+Scop (3mg/kg) & $16.04 \pm 4.78^{\mathrm{y}}$ & $2.62 \pm 3.26^{\mathrm{y}}$ & $7.98 \pm 4.26^{\mathrm{y}}$ \\
EEBP (400mg/kg)+Scop (3mg/kg) & $14.94 \pm 6.20^{\mathrm{z}}$ & $3.96 \pm 2.46^{\mathrm{z}}$ & $10.98 \pm 2.29^{\mathrm{z}}$
\end{tabular}

Values represent in mean $\pm \operatorname{SEM}(\mathrm{n}=6)$ : ${ }^{\mathrm{a}} P<0.05$, ${ }^{\mathrm{b}} \mathrm{P}<0.01$ and ${ }^{\mathrm{c}} P<0.001$ vs control rats. ${ }^{\mathrm{x}} P<0.05,{ }^{\mathrm{y}} P<0.01$ and $\mathrm{z} P<0.001$ vs Veh+ Scopolamine rats, one way ANOVA followed by Tukey's post hoc test.

\begin{tabular}{l} 
Table 2: Effect of Bauhinia purpurea and Donepezil on brain homogenates neurotransmitters content in Scop- \\
induced amnesia in rats. \\
\hline Groups \\
\cline { 2 - 3 }
\end{tabular}

Values represent in mean \pm SEM $(n=6): c P<0.001$ compared to control rats. $y P<0.01$ and $\mathrm{z} P<0.001$ compared to Scopolamine rats using one way ANOVA followed by Tukey's post hoc test.

associated with spatial learning and memory. ${ }^{33}$ Natural antioxidants are thought to be substances capable of protecting the neuronal cells from oxidative stress induced neuronal death or harm leading to cognitive deficits. ${ }^{34}$ Our current findings showed that Scop- treated group significantly increased the oxidative stress in the rat brain homogenate, as demonstrated by an increased lipid peroxidation and a reduced non-enzymatic antioxidant GSH material. Pretreated with EEBP rats attenuated the increased level of LPO and elevated the GSH content compared with Scopolamine treated group. It well confirmed with the previous studies. $^{35}$

In this study EEBP was assessed for inhibition of AChE activity, it is one of the key targets for AD therapy. Increased AChE activity contributes to a decreased level of ACh and thus neurological disorders associated with cholinergic deficiencies as seen in AD patients. ${ }^{36}$ Previous research suggested that scopolamine increases the production of AChE in both the hippocampus and cortex. ${ }^{37-39}$ Pretreated with BP extract administration significantly decreased the AChE level compared to Scopolamine treated rats. Previous report support for our present study flavonoids such as Quercetin, Kaempferol, luteolin and apigenin inhibited APP cleavage and proved to be effective anti-AD and had neuroprotective effects. Plaque deposition in extracellular spaces by aggregation of $\beta$ amyloid protein in the brain tissue is characterized by cognitive impairment. Consistent with previous findings supports for our results showed that treatment with scopolamine increase the $\beta$ amyloid ${ }_{1-42}$ level in the brain tissue as compared with the control rats. Pretreated with BP extract attenuated the scopolamine induced elevated levels $A \beta$. Earlier studies found that phytoconstituents such as alkaloids have beneficial effects on learning and memory through stimulation of cholinergic neuronal transmission and research suggested that scopolamine increases the production of AChE in both the hippocampus and cortex. ${ }^{40}$

Several studies were reported that neurochemicals such as DA, 5-HT, $\mathrm{ACh}$ and NE affects the learning and memory. Previous research suggested that scopolamine increases the production of AChE, DA and 5-HT in both the hippocampus and cortex. ${ }^{41-43}$ Current research reveals that pretreated with BP extract alter the brain neurotransmitter levels compared with scopolamine group. The neuronal damage, hippocampal edema, pyknotic cells and neuro fibrillary tangles were observed in scopolamine treated rats while groups pretreated with donepezil, BP extracts protected neurons by reversing the damage induced by scopolamine.

\section{CONCLUSION}

The observed neuroprotective and enhanced the improved in cognitive performance due to the decreased in the levels of AChE, $\beta$ amyloid, restored the neurotransmitters and prevent the oxidative damage in rat brain homogenates. These findings thus provide evidence for the potential of BP extract as a natural alternative treatment for amnesia.

\section{ACKNOWLEDGEMENT}

I wish to acknowledge the management of Crescent School of Pharmacy, B. S. Abdur Rahman Crescent Institute of Science and Technology, Vandalur, Chennai.

\section{CONFLICT OF INTEREST}

All authors declare no conflict of interest.

\section{ABBREVIATIONS}

Scop: Scopalamine; AD: Alzhemier's Disease; EEBP: Ethanolic extract of Bauhinia purpurea; LPO: Lipid peroxidation.

\section{REFERENCES}

1. Kwon SH, Lee HK, Kim JA, Hong SI, Kim HC, JoTH, et al. Neuroprotective effects of chlorogenic acid on scopolamineinduced amnesia via antiacetylcholineste 
rase and antioxidative activities in mice. Eur J Pharmacol. 2010;649(1-3):2107.

2. Ferri $\mathrm{CP}$, Prince $\mathrm{M}$, Brayne $\mathrm{C}$, Brodaty $\mathrm{H}$, Fratiglioni $\mathrm{L}$, Ganguli $\mathrm{M}$, et al. Global prevalence of dementia: A Delphi consensus study. Lancet. 2005;366(9503):21127

3. Dunning J, During MJ. Molecular mechanisms of learning and memory. Expert Rev Mol Med. 2003;5(25):1-11.

4. Ebert U, Kirch W. Scopolamine model of dementia: Electroencephalogram findings and cognitive performance. European Journal of Clinical Investigation. 1998;28(11):944-9

5. Kim E, Jung J, Jeong IH, Kim JJ, Kim DH. Ginsenosides Rg5 and Rh3 protect scopolamine-induced memory deficits in mice. J Ethnopharmacol. 2013;146(1):294-9.

6. Rountree SD, Chan W, Pavlik VN, Darby EJ, Siddiqui S, Doody RS. Persistent treatment with cholinesterase inhibitors and/or memantine slows clinical progression of Alzheimer disease. Alzheimers Res Ther. 2009;21(2):1-5.

7. Johnson WC, William OW. Warfarin toxicity. Journal of Vascular Surgery. 2002;35(1):413-31.

8. World Health Organization. Traditional Medicine, Fact Sheet, no. 134, Geneva, Switzerland. 2003.

9. Asolker LV, Kakkar KK, Chakre OJ. Part-I (A-K) New Delhi: National Institute of Science Communication; Supplement to Glossary of Indian Medicinal Plants. 2000;116-7.

10. Kirtikar KR, Basu BD. Indian Medicinal Plants. $2^{\text {nd }}$ ed. Dehradun: Oriental Enterprises. 2001;1255-7.

11. Zakaria ZA, Wen LY, Abdul RNI, Abdul HAA, Sulaiman MR, Gopalan HK Antinociceptive, anti-inflammatory and antipyretic properties of the aqueous extract of Bauhinia purpurea leaves in experimental animals. Med Princ Pract. 2007;16(6):443-9.

12. Shreedhara CS, Vaidya VP, Vagdevi HM, Latha KP, Muralikrishna KS, Krupanidh AM. Screening of Bauhinia purpurea Linn. For analgesic and anti-inflammatory activities. Indian J Pharmacol. 2009;41(2):75-9.

13. Muralikrishna KS, Latha KP, Shreedhara CS, Vaidya VP, Krupanidhi AM. Effect of Bauhinia purpurea Linn. on alloxan induced diabetic rats and isolated frog's heart. Int J Green Pharm. 2008;2(1):83-6.

14. Salatino A, Blatt CT, Santos DYD, Vaz AM. Foliar flavonoids of nine species of Bauhinia. Rev Bras Bot. 1999;22(1):17-20.

15. Yadava RN, Tripathi P. A novel flavone glycoside from the stem of Bauhinia purpurea. Fitoterapia. 2000;71(1):88-90.

16. Vijayalakshmi S, Adiga S, Bhat P, Chaturvedi A, Bairy KL, Kamath S. Evaluation of the effect of Ferula asafoetida Linn. Gum extract on learning and memory in wistar rats. Indian J Pharmacol. 2012;44(1):827.

17. Chakravarthi KK, Avadhani R. Beneficial effect of aqueous root extract of Glycyrrhiza glabra on learning and memory using different behavioral models: An experimental study. J Nat Sci Biol Med. 2013:4(2):4205.

18. Pitchaimani $V$, Arumugam $S$, Thandavarayan RA, Thiyagarajan MK, Aiyalu $R$ Sreedhar R. Nootropic activity of acetaminophen against colchicine induced cognitive impairment in rats. J Clin Biochem Nutr. 2012;50(3):2414.

19. Ohkawa H, Ohishi N, Yagi K. Assay for lipid peroxides in animal tissues by thiobarbituric acid reaction. Anal Biochem. 1979;95(2):3518.

20. Ellman G, Lysko H. A precise method for the determination of whole blood and plasma sulfhydryl groups. Anal Biochem. 1979;93(1):98102.

21. Ellman GL, Courtney KD, JrAndres V, FeatherStone RM. A new and rapid colorimetric determination of acetylcholinesterase activity. Biochem Pharmacol. $1961 ; 7(1): 8895$

22. Schlumpf $M$, Lichtensteiger $W$, Langemann $H$, Waser $P G$, Hefti F. A fluorometric micromethod for the simultaneous determination of serotonin, noradrenaline and dopamine in milligram amounts of brain tissue. Biochem Pharmacol. 1974;23(17):243746.

23. Kepe V, Barrio JR, Huang SC, Ercoli L, Siddarth P, ShoghiJadid K, et al. Serotonin
$1 \mathrm{~A}$ receptors in the living brain of Alzheimer's disease patients. Proc Natl Acad Sci USA. 2006;103(3):7027.

24. Asolkar LV, Kakkar KK, Chakre OJ. Second supplement to glossary of Indian medicinal plants with active principles. Publications and Information Directorate. 1992.

25. Patil GG, Mali PY, Bhadane VV. Folk remedies used against respiratory disorders in Jalgaon district, Maharastra. Nat Prod Radiance. 2008;7(1):354-8.

26. Dhingra $D$, Kumar $V$. Memory-enhancing activity of palmatine in mice using elevated plus maze and morris water maze. Adv Pharmacol Sci. 2012;2012(1):1 7.

27. Yildiz AF, Ulak G, Tanyeri P, Erden F, Utkan $T$, Gacar N, et al. 7nitroindazole, a neuronal nitric oxide synthase inhibitor, impairs passive-avoidance and elevated plus-maze memory performance in rats. Pharmacol Biochem Behav. 2007;87(4):43443

28. Zhao X, Liu CM, Jia Y. Timosaponin B-II ameliorates scopolamine induced cognition deficits by attenuating acetylcholinesterase activity and brain oxidative damage in mice. Metab Brain Dis. 2016;31 (6):1455-61.

29. Wilson WJ, Cook JA. Cholinergic manipulations and passive avoidance in the rat: Effects on acquisition and recall. Acta Neurobiol Exp. 1994;54(4):377-91.

30. Mansouri MT, Naghizadeh B, Ghorbanzadeh B, FarboodY. Central and periphera antinociceptive effects of ellagic acid in different animal models of pain. Eur $J$ Pharmacol. 2013;707(1-3):46-53

31. Blokland A, HonigW, RaaijmakersWG. Effects of intra-hippocampal scopolamine injections in a repeated spatial acquisition task in the rat. Psychopharmacology. 1992;109(3):373-6.

32. Ghumatkar PJ, Patil SP, Jain PD, Tambe RM, Sathaye S. Nootropic, neuroprotective and neurotrophic effects of phloretin in scopolamine induced amnesia in mice. Pharmacol Biochem Behav. 2015;135:182-91.

33. Kelleher RJ, Govindarajan A, Jung HY, Kang H, Tonegawa S. Translational control by MAPK signaling in long-term synaptic plasticity and memory. Cell. 2004:116(3):467-79.

34. Lee HJ, Lim SM, Ko DB, Jeong JJ, Hwang YH, Kim DH. Soyasapogenol B and Genistein attenuate lipopolysaccharide-induced memory impairment in mice by the modulation of NF-kB-mediated BDNF expression. J Agric Food Chem. 2017;65(32):6877-85.

35. Zhu YZ, Huang SH, Tan BKH, Sun J, Whiteman M, Zhu YC. Antioxidants in Chinese herbal medicines: A biochemical perspective. Nat Prod Rep. 2004;21(4):478-89.

36. Terry AV, Buccafusco JJ. The cholinergic hypothesis of age and Alzheimer's disease-related cognitive deficits: Recent challenges and their implications for novel drug development. J Pharmacol Exp Ther. 2003;306(3):821-7.

37. Lin J, Huang L, Yu J, Xiang S, Wang J, Zhang J, et al. Fucoxanthin, a marine Carotenoid, reverses scopolamine-induced cognitive impairments in mice and inhibits Acetylcholinesterase in vitro. Mar Drugs. 2016;14(4):67.

38. Paris D, Mathura V, Ait-Ghezala G, Beaulieu-Abdelahad D, Patel N, Bachmeier $C$, et al. Flavonoids lower Alzheimer's $A \beta$ production via an $N F_{\kappa} B$ dependent mechanism. Bioinformation. 2011;6(6):229-36.

39. Batra P, Sharma AK. Anti-cancer potential of flavonoids: Recent trends and future perspectives. 3 Biotech. 2013;3(6):439-59.

40. Mirzaev YR, Aripova SF. Neuro and psychopharmacological investigation of the alkaloids convolvine and atropine. Chem Nat Compounds. 1998;34(1):56-8.

41. Myhrer T. Neurotransmitter systems involved in learning and memory in the rat: A meta-analysis based on studies of four behavioral tasks. Brain Res Rev. 2003;41(2-3):268-87.

42. Kumar A, Singh A, Ekavali. A review on Alzheimer's disease pathophysiology and its management: An update. Pharmacol Rep. 2015;67(2):195-203.

43. Wu CR, Lin HC, Su MH. Reversal by aqueous extracts of Cistanche tubulosa from behavioral deficits in Alzheimer's disease-like rat model: Relevance for amyloid deposition and central neurotransmitter function. BMC Complement Altern Med. 2014;26(14):202.

Article History: Submission Date : 31-05-2020; Revised Date : 13-07-2020; Acceptance Date : 28-08-2020

Cite this article: Prakash R, Panneerselvam P, Dhivya R, Parthiban R, Bose SCV. Amelioration of Cognitive Deficits, Oxidative Damage, Neurochemical Alteration by Bauhinia purpurea (stem bark) on Scopolamine Induced Amnesia. J Young Pharm. 2020;12(3):231-6. 